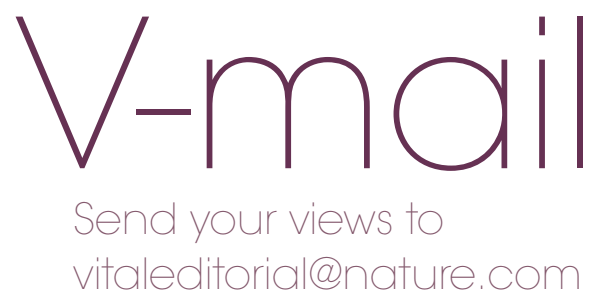

vitaleditial@ature.com

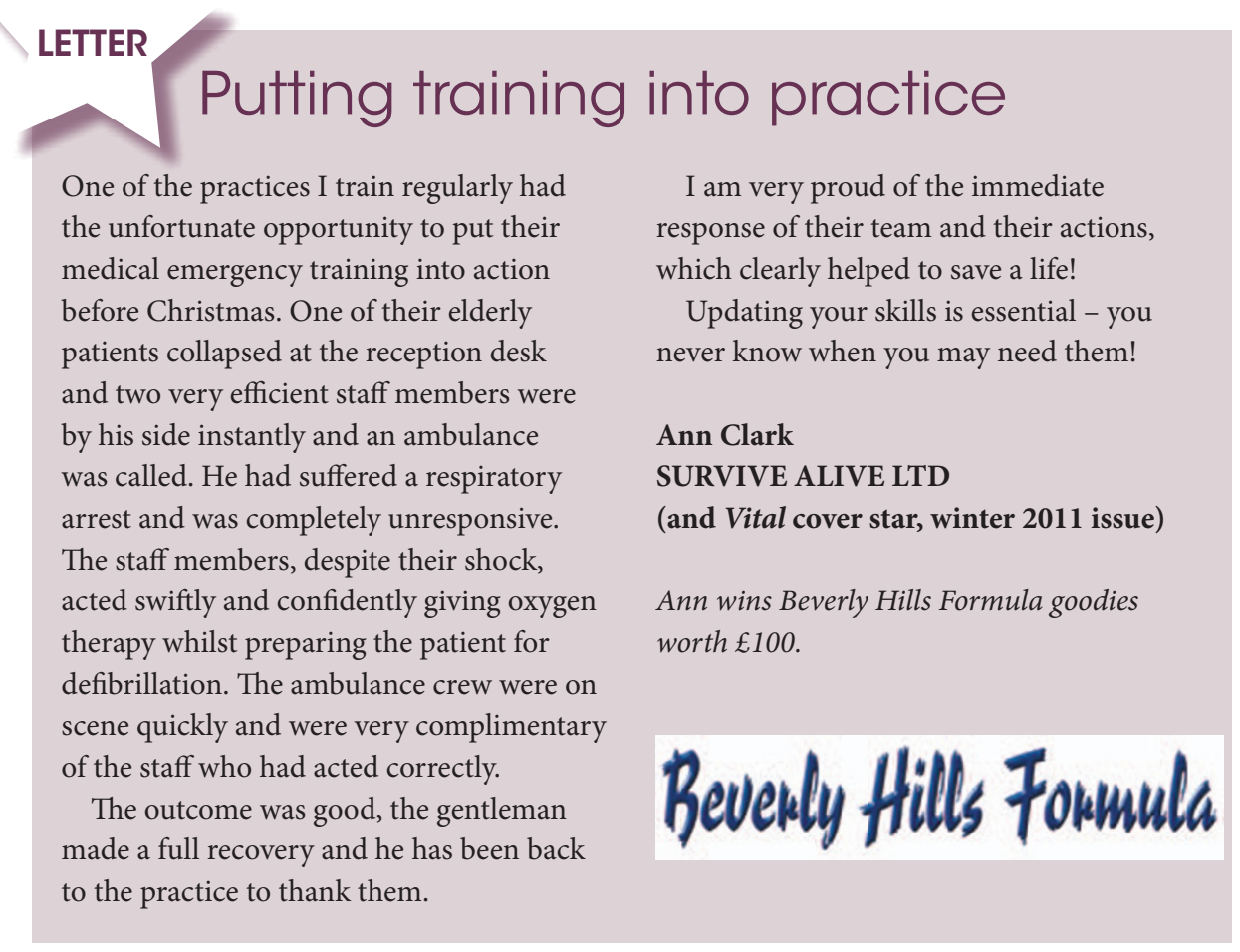

\section{WIN! 10 pairs of tickets to Grand Designs Live!}

Send your name, address and job title to vitaleditorial@nature.com or the Vital postal address (see page 5) by 13 April 2012 to be in with a chance of winning a pair of tickets to attend Grand Designs Live at Excel London between 5-13 May 2012. The show is based on the hugely popular Channel 4 TV show presented by Kevin McCloud and is the UK's number one show for design and inspiration for your home. www.granddesignslive.com

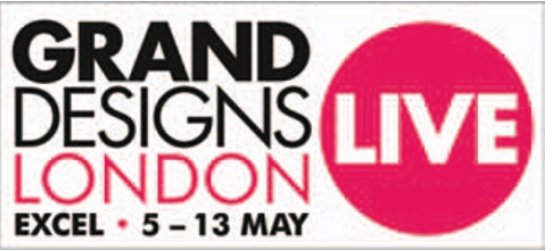

\section{A no-win situation}

I am writing in relation to the article Let your hygienist shine! (Vital autumn 2011 pages 24-26). I feel that this article does not represent the average hygienist and dental practice. I, like the majority of hygienists, work in an NHS practice but I operate on a

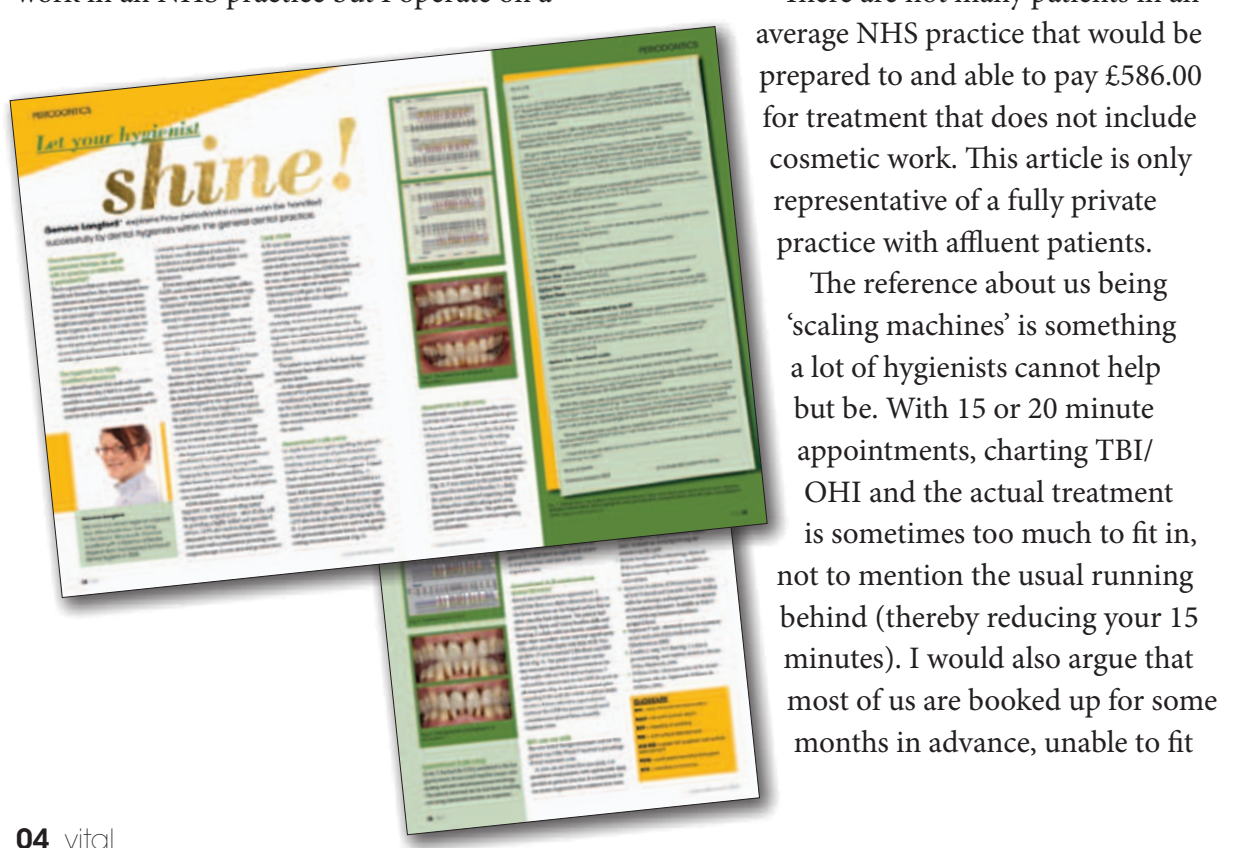

private basis. Having said that, our prices are minimal: $£ 18-£ 22$ per appointment.

Even at these prices a lot of patients find this expensive and I would be hard pushed to get a patient to agree to any more than two visits - in the current economic climate patients do not see perio treatment as vital.

There are not many patients in an average NHS practice that would be prepared to and able to pay $£ 586.00$ for treatment that does not include cosmetic work. This article is only The reference about us being 'scaling machines' is something a lot of hygienists cannot help nute $\mathrm{OHI}$ and the actual treatmen is sometimes too much to fit in, not to mention the usual running behind (thereby reducing your 15 rgue that most of us are booked up for some in $4 \times 60$ minute appointments and follow ups.

When I did work under the NHS the dentists had to stop me from doing 'prolonged perio' as patients were failing to complete the treatment due to its drawn out nature and if they did complete it would then fail to return for the final pocket chart. This meant the dentist did not get paid fully for it but had paid me so it was therefore counterproductive.

I cannot blame patients for their failure to attend; unless you have a lot of time and money, perio treatment becomes tiresome and costly. My patients who work find it hard to fit in their schedule and those that don't can't afford it.

We do refer to our nearest dental hospital who then always refer back to us asking us to complete it 'in house' due to their lack of funding (closure of perio department/ busyness!) Sometimes, to me, it appears that those with advanced perio are in a no-win situation.

\section{Hygienist from Merseyside}

